\title{
Screening for distress: Responding is a critical function for oncology nurses
}

by Margaret I. Fitch, Doris Howell, Deborah McLeod and Esther Green

\begin{abstract}
The practice of routine screening for distress in cancer populations has been gaining worldwide support over the past several years with the conceptualization of distress as the sixth vital sign. Across Canada, experience with screening for distress is growing, as cancer facilities implement screening programs. Early learning from these efforts has emphasized the need for a programmatic approach and the importance of oncology nurses in screening and providing the initial response to distress.

To date, little has been written from the nursing perspective about the oncology nursing role in a program screening for distress and responding to the identified patient concerns. This article describes the current thinking about distress; explores how screening for and responding to distress is integral to oncology nursing practice; and shares the early learning and experiences of cancer nurses in implementing screening for distress initiatives.
\end{abstract}

\section{Introduction}

The practice of routine screening for distress in cancer populations has been gaining worldwide support over the past several years with the conceptualization of distress as the sixth vital sign (Bultz \& Carlson, 2006). The Union for International Cancer Control (UICC) recently endorsed distress as the sixth vital sign, paving the way for

\section{About the authors}

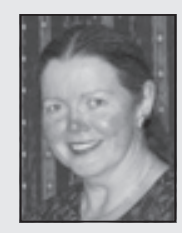

Margaret I. Fitch, RN, PhD, Head, Oncology Nursing, Co-director, Patient and Family Support, Sunnybrook Odette Cancer Centre, 2075 Bayview Avenue, T-wing, Toronto, ON M4N 3M5. Telephone: 416-480-5891; Fax: 416-480-7806; Email: marg.fitch@sunnybrook.ca

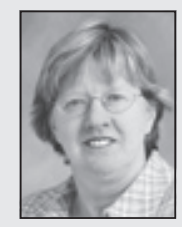

Doris Howell, RN, PhD, RBC Chair, Oncology Nursing Research, University Health Network (Princess Margaret Hospital), Associate Professor, Lawrence Bloomberg Faculty of Nursing, University of Toronto Adjunct Scientist, Cancer Care Ontario, 610 University Avenue, Room 15-617, Toronto, ON M5G 2M9. Telephone: 416-946-4501 (3419); Fax: 416-946-4585; Email: doris.howell@uhn.on.ca

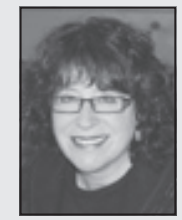

Deborah McLeod, RN, PhD, Clinician Scientist, Psychosocial Oncology Team (NSCC), QEII Health Sciences Centre, Assistant Professor, School of Nursing, Dalhousie University, Victoria 11-006, 1278 Tower Road, Halifax, NS B3H 2Y9. Telephone: 902-473-2964; Fax: 902-473-2965; Email: DeborahL.McLeod@cdha.nshealth.ca

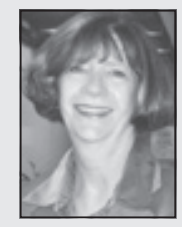

Esther Green, RN, BScN, MSc(T), Provincial Head, Nursing and Psychosocial Oncology, Clinical Lead, Patient Experience, Clinical Co-lead, Cancer Symptom Management, Cancer Care Ontario, 620 University Avenue, Toronto, ON M5G 2L9. Telephone: 416-217-1278; Fax: 416-217-1281; Email: esther.green@cancercare.on.ca universal acknowledgement of the importance of monitoring for distress (UICC, 2010). Accreditation Canada has also incorporated the expectation of routine screening for distress as a standard of care within the Qmentum Program for Cancer Care and Oncology Services (http://www.accreditation.ca/accreditation-programs/qmentum/).

Across Canada, experience with screening for distress is growing, as cancer facilities plan and implement screening programs. Early learning from these efforts has emphasized the need for a programmatic approach and the importance of oncology nurses in screening and providing the initial response to distress. Patient self-reporting of symptoms that are causing distress is the "gold standard" and an intentional effort to understand and respond to the patients' perspective is the hallmark of patient-centred care (Stewart, 2001). However, asking patients to complete a screening tool or instrument is not helpful if there is no follow-up action by health care providers based on the screening scores (Coyne, Thompson, Palmer, Kagee, \& Maunsell, 2000; Howell, Currie, Mayo, Jones, Boyle, Hack, et al., 2009).

To date, very little has been written from a nursing perspective about screening for distress and implementing a programmatic approach to screening in a clinical setting. There remains confusion on the part of nurses about how screening for distress using a standardized tool fits into their practice, and how it is different from their usual practice of assessing distress. Considerable learning is required to understand how best to incorporate standardized screening for distress into routine practice, as well as how screening can improve quality of care.

This article has several objectives: (1) describe the current thinking about screening for distress; (2) explore conceptually how screening for distress is an integral part of oncology nursing practice; and (3) share early learning/experiences of cancer nurses in screening for distress initiatives. It is anticipated that this information will help cancer nurses understand how to use a routine screening tool for the benefit of patients and enhancing person-centred care in their own practice. Sharing the early learning gleaned from actual implementation will assist others in overcoming the barriers or challenges that may emerge during the introduction of screening for distress in a clinical setting.

\section{What is distress?}

Cancer and its treatment have more than a physical impact, with emotional, psychosocial, spiritual, and practical consequences, as well (Fitch, 2008). These may occur at any time throughout the person's experience with the disease, as patients confront the reality of their situation and seek ways to cope with what is happening to them and their family. Distress is a common response across the cancer journey for both patients and their families.

Distress is conceptualized as an unpleasant experience of an emotional, psychological, social or spiritual nature that interferes with the ability to cope with cancer (NCCN, 2010). It "extends along a continuum, ranging from common normal feelings of vulnerability, sadness, and fears to problems that can become disabling, such as, depression, anxiety, panic, social isolation, and existential and spiritual crisis" (NCCN, p. 5). Identifying and responding to this distress is considered a critical aspect of quality cancer care (Carlson \& Bultz, 2003; Jacobsen, 2009; Jacobsen, Shibata, Siegel, Lee, Alemany, Brown, et al., 2009).

Distress is a dynamic phenomenon, rising and falling over time, as events unfold. In particular, it can be elevated for cancer patients at points of transition; these include such times as the initial diagnosis, start of treatment, end of treatment, at the point of recurrence, and during the last days of living (Howell et al., 2009). The proportion of patients who experience significant levels of distress has been reported 
to range from 35\% to 45\% (Zabora, BrintzenhofeSzoc, Curbow, Hooker, \& Piantadosi, 2001). Screening programs in regional cancer centres in Canada (Carlson, Angen, Cullum, et al., 2004) have documented similar rates of significant levels of distress. These levels vary by disease site, as well as by stage of disease, but are not entirely related to disease factors alone. While there are common elements to the cancer journey, no two individuals respond in exactly the same manner. Social supports, past history, coping style and a variety of other personal variables all contribute to the variation in distress (Weisman, 1976; Folkman \& Greer, 2000). Families of cancer patients are also affected by the disease of their loved ones, often experiencing emotional distress, changes in roles and relationships, financial pressure, caregiver burden, fear of losing their loved one and grief (Grunfeld, Coyle, Whelan, Clinch, Reyno, Earle, et al., 2004; Longo, Fitch, Deber, \& Williams, 2006).

There are good reasons for nurses to be alert for the signs of distress. Elevated distress is associated with poor quality of life across multiple domains (Sanson-Fisher, Girgis, Boyes, Bonevski, Burton, Cook, et al., 2000; Skarstein, Aass, Fossa, Skovlund, \& Dahl, 2000; Wen \& Gustafson, 2004). It is also linked to poor adherence to treatment regimes (Kennard, Smith, Olvera, et al., 2004), lower satisfaction with care (Von Essen, Larsson, Oberg, \& Sjoden, 2002), and unmet patient needs (Fisch, 2004; Newell, Sanson-Fisher \& Savolainen, 2002). It also accounts for additional visits to physician offices, hospital and emergency rooms, leading, ultimately, to increased costs for cancer care (Carlson \& Bultz, 2004; Carlson et al., 2004). Additionally, evidence is beginning to accumulate that distress and poor quality of life may also be associated with poor survival outcomes (Brown, Levy, Rosberger, \& Edgar, 2003; Groenvold, Petersen, Idler, Bjorner, Fayers, \& Mouridsen, 2007).

\section{Responding to distress: How are we doing?}

Across Canada, in various studies, cancer patients have indicated that they experience a number of unmet needs and low satisfaction with cancer care, especially in the areas of emotional support. While respondents rated their overall experience of care highly (95\% to 98\%); emotional support has been a weak spot that continues to receive substantially lower satisfaction scores than other dimensions with ranges of $48 \%$ to 56\% (Canadian Partnership Against Cancer, 2010). Multiple reports have been written describing patient views about what gaps exist in the cancer system and how improvements could be made (IOM, 2008, Vachon, 2006; Vachon, 1998). Patients and their families have described the characteristics they believe are important in the type of care they wish to experience. These characteristics include respect for patient preferences, physical comfort, information, education and communication, coordination and continuity of care and ease of access to services (Gerteis, Edgman-Levitan, Daley, \& Delbanco, 1993).

Despite the evidence that cancer patients experience unmet needs and distress, identification and reporting of that distress is often not done routinely in daily clinical practice (IOM, 2008; Vachon, 2006; Plummer, Gourney, Goldberg, et al., 2000; Merckaert, Libert, Delvaux, et al., 2005). A number of factors influence nurses in terms of their identification, assessment of and response to distress. Many doctors and nurses believe they do assess for distress quite well and a more standardized approach is not needed. However, studies show that oncologists and nurses are not always accurate in identifying patients with significant distress (Fallowfield, Ratcliffe, Jenkins, \& Saul, 2001; Mitchell \& Kakkadasam, 2010; Mitchell, Hussain, Grainger, \& Symonds, 2010). Nurses report concerns about time constraints preventing more consistent holistic assessments or they feel unprepared to handle the patient's emotional responses that emerge (McLeod, Tapp, Moules, \& Campbell, 2010; Botti, Endacott, Watts, Cairns, Lewis, \& Kenny, 2006). It is likely that these two factors are linked (McLeod, et al., 2010). Others are concerned about the availability of services where patients could be referred to address the psychosocial issues and concerns that are identified. In one study, while nurses did not assess psychosocial distress in any standardized way, when patients or family members asked for help in this area, the help they received generally was reported as very helpful and met the need (McLeod \& Morck, 2011).

While patients may receive help when they ask, there are a number of reasons that likely contribute to the failure to volunteer the fact that they are distressed, or to accept help when it is offered. The words "emotional" or "psychological" or "psychiatric" are stigmatized and individuals do not want to be labelled as such (Barney et al., 2009; Holland, Kelly, \& Weinberger, 2010). Patients and family members have concerns about being perceived as weak and unable to manage. Additionally, patients believe that doctors and nurses are too busy with other patients' treatment concerns and are not interested in the emotional or practical issues (McLeod et al., 2010; Steele \& Fitch, 2008). Patients also may be concerned that their treatment could be stopped if they report distress related to uncontrolled side effects or that they may distract their health team from focusing on their treatment. Others have identified that patients vary in their ability to volunteer information and providers vary in their ability to elicit information (IOM, 2008; Richardson, Medina, Brown, \& Sitzia, 2007). It seems very clear that psychosocial and supportive care needs will be unmet unless systematic assessment processes to identify the individual's specific problems and needs are a consistent part of routine clinical practice (Holland, Kelly, \& Weinberger, 2010; Mitchell et al., 2010). Even when distress is identified, however, there are reasons why help may not be accepted.

In several studies, as many as half of the patients who indicated they were experiencing distress because of unmet needs also indicated they did not want assistance at the time of the assessment (Carlson et al., 2004; Fitch, in press; Steele \& Fitch, 2008). In a recent qualitative study, patient's perspectives regarding the desire for assistance were explored (Steele \& Fitch, 2008). The reasons patients indicated they did not want help for unmet needs at a specific point in time were quite varied, including: thinking the concern was expected with cancer treatment and nothing could be done about it (e.g., fatigue); not knowing a service existed and was available to them (e.g., sexuality clinic); believing the cancer care team would be too busy or not interested in helping them with an issue (e.g., how to tell children about diagnosis); and feeling they already had enough to cope with and could not deal with anything more right now.

Recent reports from governmental bodies and leading advocacy agencies have begun to call for improved person-centred or whole person care (Institute of Medicine, 2008; Gerteis et al., 1993). National and regional cancer control strategic plans contain reference to the inclusion of person-centred care as a hallmark of comprehensive quality cancer care, pointing to the need for whole person assessment and care. Many of the strategic plans incorporate goals about improving the patient experience and decreasing the burden of suffering and emphasize the need to make use of the existing body of evidence to intervene appropriately. There is a robust and growing body of research evidence concerning communication; provision of information and support; management of emotional, psychosocial, and spiritual needs; as well as pain and other symptoms (Hack, Degner, \& Parker, 2005; Lepore \& Coyne, 2006; Patrick, Ferketich, Frame, Harris, Hendricks, Levin, et al., 2003). However, it is of critical importance to have concrete strategies and structured, clearly defined approaches and a programmatic structure established in order to achieve the desired outcomes.

\section{A national response: Screening for distress}

For busy clinical settings, one concrete strategy recommended to move toward person-centered care is to screen for distress using a standardized tool (Holland, Kelly \& Weinberger, 2010; NCCN, 2010; Howell et al., 2009). Screening is a specific strategy to help identify those individuals with elevated distress who are in need of additional assessment and intervention. Screening is defined as a rapid method of prospectively identifying individuals who are experiencing difficulty. It is a method of triage or rapid identification, as well 
as a mechanism for the patient to indicate what is of concern or a problem to him or her at a specific point in time. This indication of concern is a starting point for a person-centred therapeutic relationship between the care provider and the patient. Effective communication and establishment of a therapeutic relationship (Hack, Degner, \& Parker, 2005) is fundamental to a deeper assessment and an appropriate response or referral to other relevant services (Howell et al., 2009). Using a standardized tool for screening offers a consistency in data capture and is valuable for comparison over time. It also cues patients with regard to areas that the health care team is concerned about and will monitor over time.

To be successful, screening cannot stand alone. The practice of screening must be embedded in a programmatic approachscreening followed by appropriate assessment using a valid tool to understand the parameters of a specific problem identified with appropriate follow-up action to screening results. Establishing a screening program requires consideration of several program elements: selection of a reliable/valid screening tool; distribution of the tool to the patients; retrieval of the completed tools; scoring of the tool and categorization of the scores; and implementing localized pathways for action based on the scores, including referral of patients with elevated scores and follow-up with the referred patients. Screening must be embedded in a therapeutic relationship (Hack, Degner, \& Parker, 2005) with health professionals who can initiate interventions to address the distress or refer to specialized professionals and programs.

At present, in Canada, considerable effort has been undertaken to develop guides for screening for distress and tools to assist clinicians as they implement programmatic approaches (Screening Toolkit, Canadian Partnership Against Cancer [CPAC]). A minimum data set has been identified with the Edmonton Symptom Assessment System (ESAS) (Bruera, Kuehn, Miller, Selmser, \& Macmillan, 1991) and the Canadian Problem Checklist recommended for use to capture data regarding a broad range of physical, psychosocial and practical problems or concerns common in cancer (CPAC, 2009). A conceptual framework for guiding the assessment process and response to scores on the ESAS has been identified (Howell et al., 2009) (See Figure 1). Recommendations have been made that scores of 1 to 3 on the ESAS items suggests low distress, scores of 4-6 suggests moderate distress, and 7 and above are severe distress (Bruera et al., 1991; Cleeland et al., 1994). The low scores need to be acknowledged by the clinician, but may not require additional intervention beyond standard care assuming that it is of high quality and inclusive of good symptom management, easy access to relevant information, basic emotional support, and effective communication between patient and providers (Fitch, 2008). Moderate level scores need more assessment to determine what factors are related to onset and severity, what the impact is on the person, what strategies have been effective in managing the symptom so far, and the person's wishes or goals with regard to addressing the symptom. Then, interventions are offered to prevent further escalation

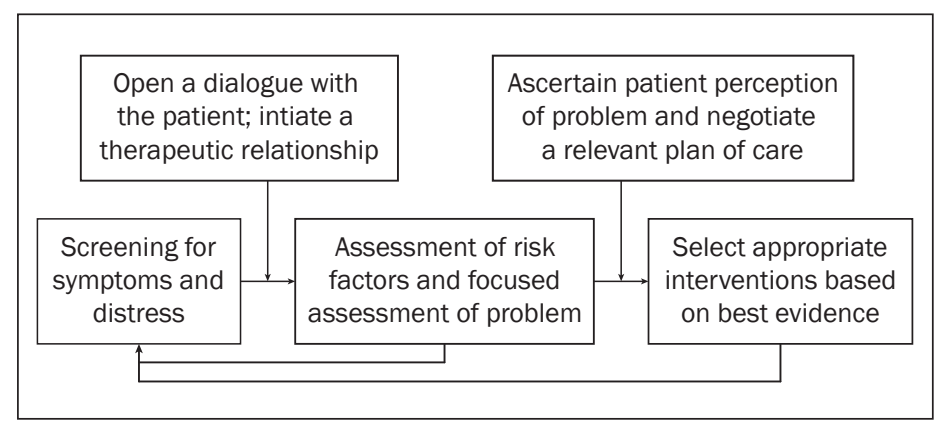

Figure 1. Conceptual framework for guiding the assessment and response to ESAS Scores and to alleviate the symptom. The highest scores require immediate comprehensive and focused assessment and intervention to alleviate the symptom, treat the problem, and reduce the burden on the patient and family (i.e., at the time of the clinic visit, or by phone, or tele-health/videoconference) (See Figure 2 for scoring algorithm).

\section{Role of oncology nurses in screening for distress}

The Canadian Association of Nurses in Oncology has clearly articulated the role of the specialized oncology nurse and outlined both standards of care (what the patient can expect to receive) and practice competencies (what the nurse is expected to provide in caring for cancer patients and their families) (www.cano.ca). Key responsibilities of the specialized oncology nurse include managing symptoms, teaching and coaching, and assisting patients and families to cope with the consequences of the disease and treatment. These responsibilities cannot be completed without astute assessment using valid tools. In turn, that assessment needs to start with, and be based on what is important and of concern to the individual patient. Given that distress is a nurse-sensitive outcome (Howell, 2010), oncology nurses have a key role in responding to distress screening scores and the multidimensional factors that contribute to distress.

Screening for distress using a standardized tool, such as ESAS and the Canadian Problem Checklist, provides nurses with an initial understanding of the levels of physical and psychological symptom severity and the main problems or issues faced by the patient. The nurse's review of the scores on the screening measure can serve as a mechanism for triage and can facilitate setting priorities for intervention. Routine screening helps to focus the conversation between the patient and the nurse on the sources of distress experienced by the patient. By starting the conversation with the intention of determining the source of the rating of the distress, the nurse can assess needs in a more focused way and intervene appropriately regarding the distress. Interventions by oncology nurses include establishing therapeutic relationships, providing education and supportive counselling, and making appropriate referrals to professional and community services (Corner, 1996; Arnold, 1999).

Responding to distress has figured prominently in nursing practice and nursing intervention taxonomies (McCloskey \& Bulechek, 1996) and distress is considered amenable to nursing interventions (Given \& Sherwood, 2005; Fulcher, Badger, Gunter, \& Marrs, 2008).

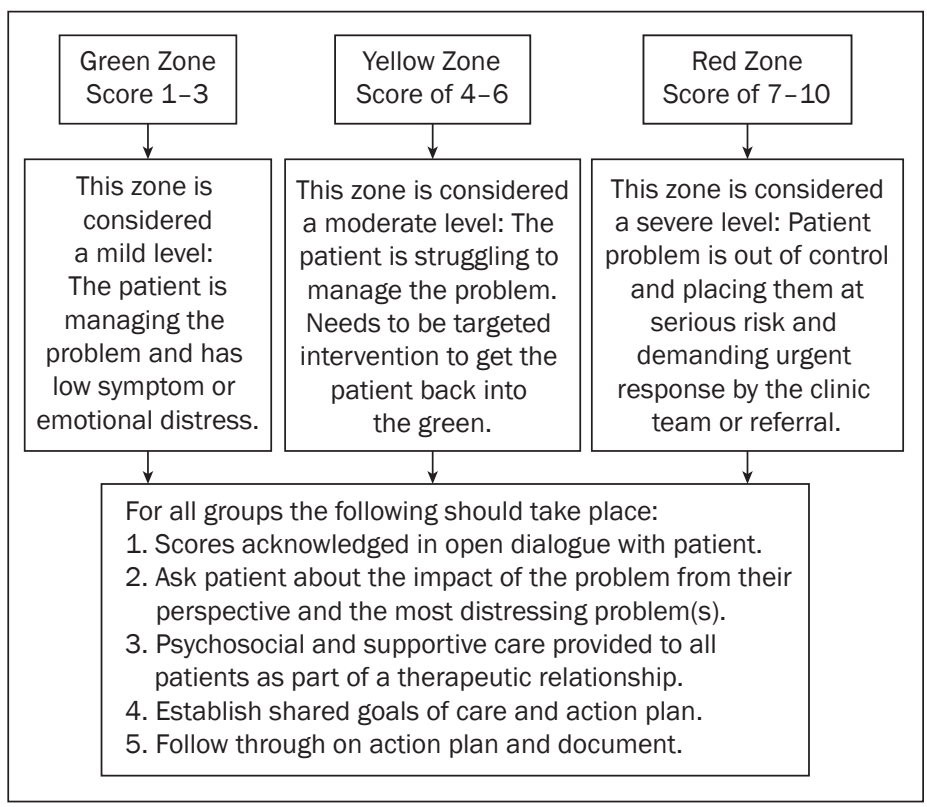

Figure 2: Scoring algorithm for responding to distress scores 
Responding to distress is considered an important part of nursing practice, as part of a therapeutic person-centred care approach (MacCormack \& McCance, 2006) and interpersonal communication with patients facing illness stressors (Arnold, 1997). Nurses are the cornerstone to effective relief of pain and other symptoms (McCaffery \& Pasero, 1999). Patient education or psycho-educational interventions along with relaxation and non-pharmacological interventions delivered by nurses are shown to be effective (Howell, 2010). Outcome-based assessment is recommended, as part of best practice in nursing (Kleinpell, 2001), and the use of standardized self-report instruments in screening programs provides data to monitor changes in patient response to cancer and treatment over time and allows nurses to gauge the effectiveness of interventions. However, nurses express concern about not feeling valued as contributors in the provision of psychosocial care to reduce distress (Botti et al., 2006) and have expressed a number of additional concerns, as distress screening has evolved across Canada.

Nurses have indicated anecdotally that they are reluctant to screen patients when they don't have resources to assist them to make decisions regarding further assessment and interventions. Careful attention is required to provide localized care pathways for follow-up action and clear expectations about the use of evidence in clinical decision-making regarding intervention selection. Currently, provincial cancer agencies and the Cancer Journey Action Portfolio of the Canadian Partnership Against Cancer are leading the way with the production of clinical practice guidelines and brief algorithms to guide practice related to physical and psychological symptom scores on the ESAS. Recently completed guides include, for example, those on depression and anxiety, fatigue, sleep disturbances (Howell, 2010), pain, dyspnea, and nausea and vomiting for palliative populations (Cancer Care Ontario, 2011) (See Figure 3, pages 16-17 for example). More guides are in the planning stages and both provincially and nationally efforts are being made to incorporate these guides in practice. For example, Cancer Care Ontario has developed applications on hand-held devices (iPhone apps; Windows Phone 7) to allow easy access to the algorithms wherever the nurse and patient are located, thus overcoming the reliance on paper or access to computers.

Ultimately, localized care pathways need to be organized for the specific actions in a local setting. Introducing a programmatic screening approach requires a clear designation about who will respond to the scores initially, and how assessment and intervention will occur by members of specific disciplines within specified scopes of practice. It is important that one does not screen without follow-up and action based on the screening results or scores. This requires an inter-professional team approach in the clinical setting together with effective partnerships with community-based organizations. Frequently, the full range of services cannot be available in one facility. However, the full complement of services may be available across a region and made available to patients and families through partnership arrangements (Fitch, 2008).

Figure 4 (page 18) outlines the generic process a nurse would follow in responding to screening scores from a standard tool in a clinical situation. When the patient completes the screening instrument (either on paper or on a computer touch screen) the nurse uses the results to open the dialogue and further assess the intensity of the concern, its impact and meaning for the patient. This opening conversation provides a brief review of the patient responses on the screening tool and the patient's reasons for answering with specific scores. Based on what is shared during this interaction, the nurse must decide about the need for further exploration of the concerns and a more focused assessment. As the nurse learns more from the patient about his or her situation, the nurse determines the necessary course of action or intervention. The nurse intervenes with non-pharmacological approaches within the scope of the specialized oncology nursing role or may consult with other members of the health care team and intervene through a collaborative approach (for example, advocating for pharmacological interventions, such as pain analgesics). The nurse may also refer the patient to another member of the inter-professional team for specific assessment and intervention.

\section{What are the challenges and barriers in introducing a standardized screening tool?}

To date, relatively little has been written about implementing a screening for distress program from a nursing perspective, or about the challenges that could be experienced. Vodermaier and Linden (2008) reported that $36.5 \%$ of the 146 respondents to their national survey of Canadian cancer programs were using a standard tool for distress screening in their practice settings. The challenges reported concerning the difficulties in implementing the use of a standardized tool included time pressures for staff to complete and score the screening tool $(\mathrm{n}=11)$, difficulties in applying the screening in a consistent manner $(n=9)$, attitudinal buy-in by health care staff $(n=9)$, and problems with follow-through once a positive screening result was obtained $(n=4)$. This work did not focus specifically on nursing perspectives.

In preparation for this manuscript, oncology nursing leaders who have been engaged in implementing screening for distress programs were consulted regarding the key challenges and benefits for oncology nurses that they had observed as they engaged in implementing a screening for distress program. The perspectives these nurse leaders described regarding implementation of screening for distress are summarized in Table 1 (page 18).

The major challenges for oncology nurses revolved around the understanding and beliefs about screening and the current interpretation of the oncology nursing role. A primary challenge was the perception of screening as an "add on" to daily work rather than seeing it as an aid to triage and an integral part of nursing practice. A second major challenge revolved around the interpretation of the oncology nursing role in many cancer programs. The nurse leaders shared the perspective that the role of the oncology nurse has been eroded over the last decade because of a number of workload and organizational factors. The result is a wide variation in practice concerning oncology nurses' engagement in psychosocial assessment and intervention. Screening for distress implementation provides an opportunity to reaffirm this important aspect of practice. However, success will require nursing staff to embrace distress as a nurse sensitive outcome and gain comfort and confidence in providing effective psychosocial care and evidence-based symptom management.

The benefits oncology nurse leaders have observed during their exposure to screening for distress implementations are also listed in Table 1. A key benefit has been the reaffirmation and acknowledgement of the role of nurses as specialized oncology nurses with key contributions to make in managing symptoms and psychosocial distress. The nursing staff members have been able to focus their practices and enhance their capacity to engage in assessment and intervention regarding both psychosocial care and symptom management. Nursing leaders see that the psychosocial care of patients has been improved and is focused on what patients are saying is important to them. The conversations between nurses and patients are including topic areas that were not part of the conversations nurses and patients had been having in the past. Patients' perceptions about what is important to them serve as the starting point for the dialogue with patients.

These nurse leaders also identified critical success factors in implementing screening for distress as a programmatic approach (See Table 1). An essential factor in achieving the desired outcome is the access nurses have to appropriate practice-based education and clinical support during the implementation of screening for distress. Providing education has been a key strategy to help nurses know how to perform effective psychosocial assessments and symptom management interventions in busy clinical environments.

continued on page 18. 


\section{ALGORITHM: \\ Pain in Adults with Cancer: Screening and Assessment}

\section{Screen for pain using ESAS at each visit}

ESAS score 1 to 3

ESAS score 4 to 6

ESAS score 7 to 10

Assessment using Acronym O, P, Q, R, S, T, U and V (adapted from Fraser Health)

\begin{tabular}{c|l}
\hline Onset & When did it begin? How long does it last? How often does it occur? \\
\hline Provoking/Palliating & What brings it on? What makes it better? What makes it worse? \\
\hline Quality & What does it feel like? Can you describe it? \\
\hline Region / Radiation & Where is it? Does it spread anywhere? \\
\hline Severity & $\begin{array}{l}\text { What is the intensity of this symptom (On a scale of 0 to 10, with 0 being none and } 10 \text { being worst possible)? Right Now? At Best? At Worst? } \\
\text { On Average? How bothered are you by this symptom? Are there any other symptom(s) that accompany this symptom? }\end{array}$ \\
\hline Treatment & $\begin{array}{l}\text { What medications or treatments are you currently using? How effective are these? Do you have any side effects from the } \\
\text { medications/treatments? What medications/treatments have you used in the past? }\end{array}$ \\
\hline Understanding / & What do you believe is causing this symptom? How is this symptom affecting you and/or your family? \\
\hline Values & $\begin{array}{l}\text { What is your goal for this symptom? What is your comfort goal or acceptable level for this symptom (On a scale of } 0 \text { to } 10 \text { with 0 being none } \\
\text { and } 10 \text { being worst possible)? Are there any other views or feelings about this symptom that are important to you or your family? }\end{array}$ \\
\hline
\end{tabular}

* Physical Assessment (focus on area of pain to determine cause and type of pain ); Pertinent History (risk factors); Assess risks for addiction; Associated symptoms: e.g. nausea, vomiting, constipation, numbness, tingling, urinary retention.

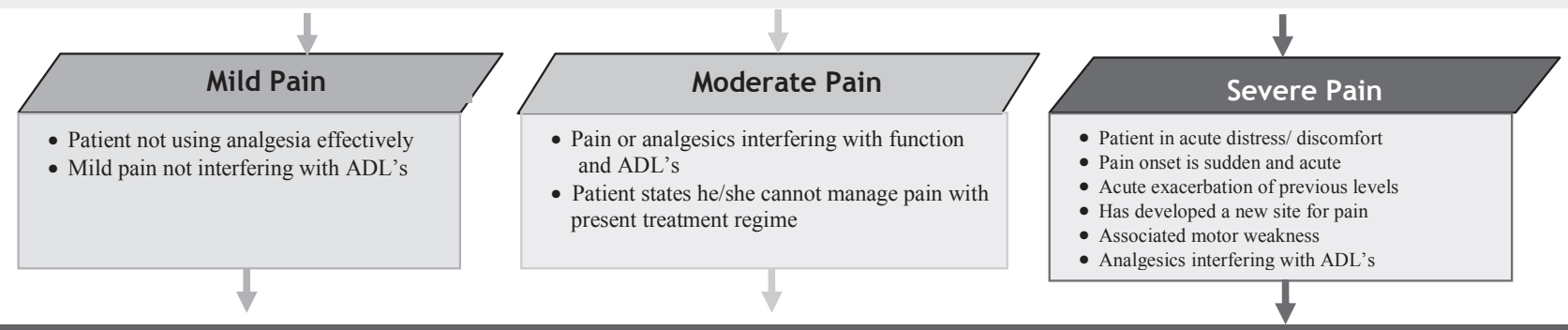

Interventions for all patients, as appropriate

NON-PHARMACOLOGICAL

- Psycho-social-spiritual interventions (patient education, counseling, recreational activities, relaxation therapy imagery, social interaction, spiritual counselling).

- Other therapies (physiotherapy, occupational therapy, massage, aromatherapy, music therapy, acupuncture, transcutaneous electrical nerve stimulation, reflexology, Reiki, hypnotherapy).

- Other interventions such as radiation therapy, vertebroplasty, surgery and anesthetic interventions should be considered in patients with difficult to control pain.

Patient Education

- Taking routine and breakthrough analgesics, adverse effect management, non pharmacologic measures that can be used in conjunction with pharmacologic treatment.

PHARMACOLOGICAL

- The severity of pain determines the strength of analgesic required specified by the World Health Organization (WHO) Analgesic Ladder.

- The type and cause of the pain will influence the choice of adjuvant analgesic (e.g. nociceptive, neuropathic, bone metastases).

- In the presence of reduced kidney function all opioids should be used with caution and at reduced doses and/or frequency.

- Fentanyl, methadone and oxycodone are the safest opioids of choice in patients with chronic kidney disease.

- Methadone requires an experienced prescriber, check for significant drug interactions before prescribing any drug to a patient on methadone.

- When using a transmucosal fentanyl formulation for breakthrough pain the effective dose should be found by upward titration independent of the regular opioid dose.

- For those with stabilized severe pain and on a stable opioid dose or those with swallowing difficulties or intractable nausea and vomiting, fentanyl transdermal patches may be appropriate, provided the pain is stable.

- Classify the pain - nociceptive, neuropathic or mixed?

- The type and cause of the pain will influence the choice of adjuvant analgesic (e.g. nociceptive, neuropathic, bone metastases).

- The choice of antidepressant or anticonvulsant should be based on concomitant disease, drug therapy and drug side effects and interactions experienced.

- There is insufficient evidence to support a recommendation for topical opioids.

- There is insufficient evidence to support first or second line therapy of cancer pain with cannabinoids but they may have a role in refractory pain, particularly refractory neuropathic pain.

- Transdermal fentanyl should not be used in opioid naïve patients.

- Specialist palliative care advice should be considered for the appropriate choice, dosage and route of opioid in patients with reduced kidney function or in patients with difficult to control pain.

\section{ADVERSE EFFECTS OF OPIOIDS}

- Many opioid-naïve patients will develop nausea or vomiting when starting opioids, tolerance usually occurs within 5-10 days. Patients commencing an opioid for moderate to severe pain should have access to an antiemetic to be taken if required.

- The majority of patients taking opioids for moderate to severe pain will develop constipation. Little or no tolerance develops. The commonest prophylactic treatment for preventing opioid-induced constipation is a combination of stimulant (senna or bisocodyl) and osmotic laxatives (lactulose or PEG 3350).

\section{Figure 3a: Pain in adults with cancer: Screening and assessment}




\section{Pain in Adults with Cancer: Care Map}

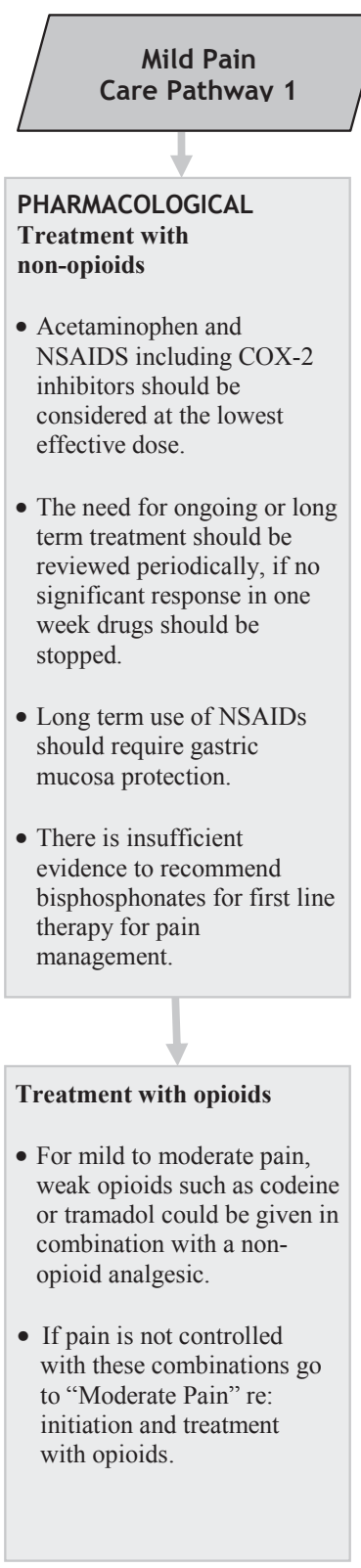

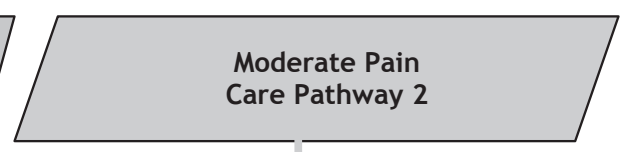

\section{PHARMACOLOGICAL}

Treatment with opioids

- If the person is opioid naïve:

o Morphine starting dose is usually $5 \mathrm{mg}$ Q4h with 2.5-5mg Q1H prn for breakthrough pain. For elderly or debilitated patients consider a starting dose of $2.5 \mathrm{mg}$ Q4h.

o Hydromorphone starting dose is $1 \mathrm{mg}$ Q4h with $0.5-1 \mathrm{mg}$ Q1h prn for breakthrough pain. For elderly or debilitated patients consider a starting dose of $0.5 \mathrm{mg}$ Q $4 \mathrm{~h}$.

o Oxycodone starting dose is $2.5 \mathrm{mg}$ or one half tablet Q4H with $2.5 \mathrm{mg}$ or one half tablet Q2H prn for breakthrough.(The lowest dose oxycodone tablets available, either in combination with acetaminophen or alone, contain $5 \mathrm{mg}$ of oxycodone, equivalent to $\sim 5-10 \mathrm{mg}$ of morphine).

- If the person is taking an opioid:

o As an immediate release preparation with $\mathrm{q} 4 \mathrm{~h}$ dosing, increase the regular and breakthrough doses by $25 \%$.

- As a sustained release opioid, increase this dose by $25 \%$. Change the breakthrough dose to $10 \%$ of the regular $24 \mathrm{~h}$ dose, either q1-2h PRN PO or q30 min PRN subcut.

o Patients with stable pain and analgesic usage, receiving oral morphine, oxycodone or hydromorphone should have the drug converted to a sustained or controlled release formulation given $\mathrm{q} 12 \mathrm{~h}$ for ease of administration. The short acting breakthrough dose is usually $10 \%$ of the total daily dose.

o The frequency of breakthrough doses for oral opioids is Q1-2h prn. After conversion to a long acting preparation, if pain is not well controlled, reassess the patient and consider why multiple breakthrough doses are being used and the effectiveness of the breakthrough doses.

o If indicated after proper assessment, the daily dose can be titrated by adding 20 to $30 \%$ of the breakthrough doses used in the preceding $24 \mathrm{hrs}$ to the daily sustained release formulation.

o Make frequent assessments and adjustments to the opioid dose until the pain is better controlled.

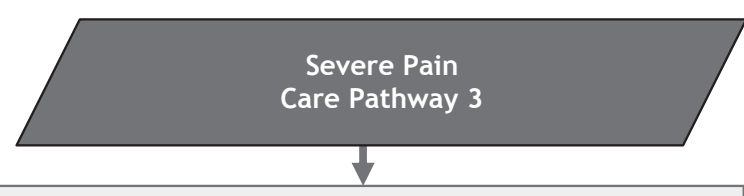

PHARMACOLOGICAL

Treatment with strong opioids

- If the person is opioid naïve: Oral: Morphine 5-10 mg PO q4h and 5mg PO q1h PRN OR hydromorphine 1.0-2.0 mg PO q4h and $1.0 \mathrm{mg}$ PO q1h PRN OR Subcutaneous: Morphine 2.5 - 5 mg subcut q4h \& $2.5 \mathrm{mg}$ subcut q30min PRN OR hydromorphone $0.5-1.0 \mathrm{mg}$ subcut $\mathrm{q} 4 \mathrm{~h} \& 0.5 \mathrm{mg}$ subcut $\mathrm{q} 30 \mathrm{~min}$ PRN.

- If the patient is taking an opioid with $\mathrm{q} 4 \mathrm{~h}$ dosing, increase the regular and breakthrough doses by $25 \%$. Change frequency of the breakthrough to q1h PRN if PO and q30min PRN if subcut.

- If the patient is taking a sustained release opioid, increase this dose by $25 \%$. Change the breakthrough dose to $10-15 \%$ of the regular 24h dose, either q1h PRN PO or q30 min PRN subcut.

- Titrate the dose every $24 \mathrm{~h}$ to reflect the previous $24 \mathrm{~h}$ total dose received

- If unmanageable opioid-limiting adverse effects are present (e.g. nausea, drowsiness, myoclonus), consider switching to another opioid and re-titrate or consult palliative care.

- For patients with severe uncontrolled pain consider switching back to an equivalent daily dose of immediate release morphine to allow more rapid titration of dose or switch to a sc preparation/infusion.

- Meperidine and pentazocine should generally not be used in cancer patients with chronic or acute pain.

- If there is difficulty getting the pain under control consider a consultation to palliative care.

\section{SEVERE PAIN CRISIS}

1. A severe pain crisis requires prompt use of analgesics, adjuvant therapies, reassurance and a calm atmosphere.

2. Consider a consultation to palliative care or a cancer pain specialist.

3. If IV access is present, and the person is opioid naïve give stat morphine $5-10 \mathrm{mg}$ IV q10min until pain is relieved; if the person is on opioids give the po prn dose IV q10min until pain is relieved. Monitor carefully.

4. If no IV access available, and the person is opioid naïve give stat morphine 5-10 mg subcut q20-30min until pain is relieved; if the person is on opioids give the po prn dose subcut q20$30 \mathrm{~min}$ until pain is relieved.

5. Titrate dose by $25 \%$ every $1-2$ doses until pain is relieved.

6. When pain is controlled: If the patient is taking a sustained release opioid increase this dose by $25 \%$ and change to $\mathrm{q} 4 \mathrm{~h}$ dosing po or subcut. Do Not try to manage a severe pain crisis with a long-acting opioid. Change the breakthrough dose to half of the regular dose, either q1h PRN PO or q30 min PRN subcut.

Follow-Up and ongoing Monitoring

If pain remains unrelieved despite the approaches outlined above, request the assistance of a palliative care consultation team

For full references and more information please refer to CCO's Symptom Management Guide-to-Practice: Pain document.

Disclaimer: Care has been taken by Cancer Care Ontario's Algorithm Development Group in the preparation of the information contained in this Algorithm. Nonetheless, any person seeking to apply or consult the guidance for practice document is expected to use independent clinical judgment and skills in the context of individual clinical circumstances or seek out the supervision of a qualified specialist clinician. CCO makes no representation or warranties of any kind whatsoever regarding their content or use or application and disclaims any responsibility for their application or use in any way. 


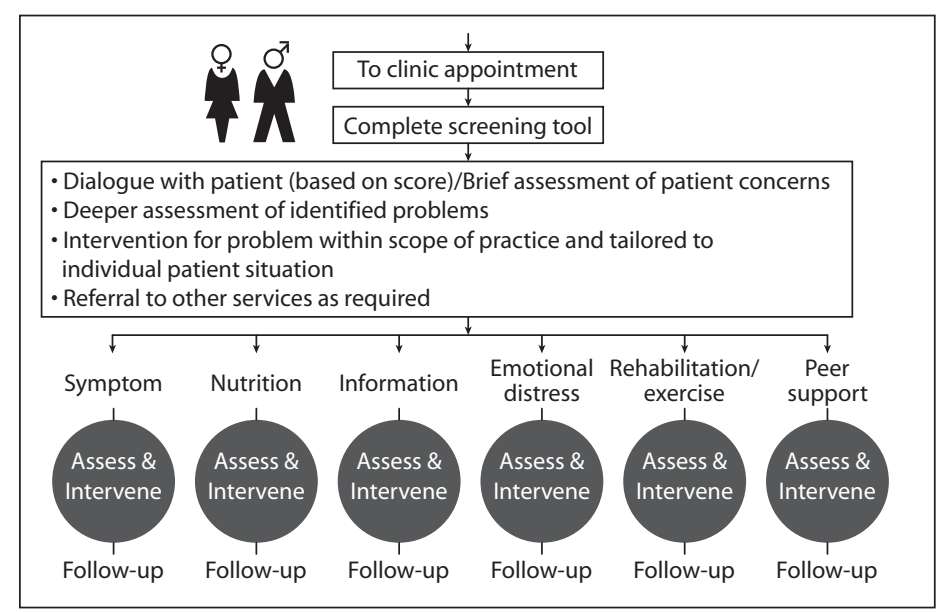

Figure 4: Screening assessment intervention process for whole person care

\section{Meeting the education needs of nurses}

As articulated above, nurses need to understand the screening process, how to interpret scores and the guidelines to address identified problems. Nurses also need to feel confident about their ability to implement these tools and guidelines smoothly and efficiently within the context of their daily practice. In the national screening for distress project, local implementation teams address some of these needs. In addition, however, a national education program providing more in-depth education was created to support nurses, as they implemented screening programs.

The Inter-professional Psychosocial Oncology Distance Education (IPODE) project, an initiative of the Canadian Association of Psychosocial Oncology (CAPO), developed a program with funding from the Canadian Partnership Against Cancer. This six-hour independent study program is freely available on-line (www.ipode. $\mathrm{ca} /$ screening) and addresses such things as the need for screening, how to discuss screening results with patients and family members, and how to handle referrals. It also provides a review of therapeutic relationships, communication and supportive counselling. The program was launched in 2010 and, to date, has had more than

Table 1. Screening for distress: Nurse-perceived challenges, benefits and critical success factors in uptake and utilization

Challenges (fears, concerns and
potential barriers)
potential barriers)

- workload will be increased by adding on screening

- flow of clinic appointments will be delayed as clinicians manage screening issues

- there is not enough time to do screening and patients will not fill in long forms

- screening is not part of their (nurses') role or responsibility

- screening is just one more thing that has been added onto the day's work and is just one more questionnaire to be filled in

- patients do not want help with some of the issues, so why bother screening

- screening and talking about the issues will add to the patients' distress

- they are already doing screening about the issues anyway and the tool will not add anything additional

- how to deal with the distress and concerns that are identified; how to deal with all the issues that will emerge

- there will be no place or service where referrals can be made once patient problems are identified

- existing services will be overwhelmed by the number of referrals that will be needed once screening happens - confusion between screening and assessment

- which tool(s) to use-are they appropriate for all populations, all settings, all stages of cancer experience?
Critical success factors for uptake of screening for distress

- engaged and effective nursing leaders with clear vision for nursing and patient care

- clinical champions within nursing who support and teach other nurses

- advanced practice nurses who work in collaboration with registered nurses and other members of the team to support practice change

- senior leaders with a vision for patient-centred care

- electronic tools and resources to support both the patients and the nurses

- managers who actively support the front-line staff members to engage in nursing practice

- involvement of staff in planning the process steps for screening and the implementation plan

- engagement of the inter-

professional team in designing care pathways for the implementation

- clearly articulated roles and responsibility of each discipline for screening follow-up actions within their respective scopes of practice

- clearly articulated set of process steps (in detail) regarding the screening policies and procedures

- availability of meaningful clinical supports for the staff (e.g., tools, education, mentors)

- system to track and report on progress with implementation

- infrastructure to support sustainability

- persistent and long-term efforts to implement and sustain momentum
Benefits of screening for distress with active engagement of oncology nurses

- the nursing role in psychosocial care and symptom management has been reaffirmed, profiled and acknowledged; nurses are in first place as responders and able to show clearly what they are capable of contributing to patient care; their activities are focused and streamlined

- psychosocial care for patients has been strengthened and enlarged; patient issues are being identified that were not before screening was introduced; patient stories about the impact of cancer are emerging and what is important to them is being stated; patients are supported to bring forward their concerns to nurses to be addressed (patient-centred care is realized)

- patients report that their care experience meets their needs; that nurses are responsive to their symptoms and that the nurses provide comfort, both physical and emotional on a consistent basis being able to focus the conversation streamlines interaction and can save time; "you are going down the right road sooner"; the tool is most useful in focusing conversations

- the teamwork is more cohesive and collaborative; professions are more aware of one another's scope of practice; communication among the team members is improved; the team members are all talking the same language

- having screening for distress introduced is driving practice change and is shaping practice; there is more consistency and continuity of nursing care; the workflow and workload is shifting; nurses are taking more leadership around psychosocial care and symptom management

- the referrals to other disciplines address key issues within their scope of practice

- documentation is more apt to occur

- tracking and monitoring individual patient concerns is easier to assess the impact of screening and interventions

- having an organized database with our own patients' information is very powerful; we can review trends in patient concerns and use the data for program planning and resource allocation arguments; you can see where the gaps are in services

- the needs for education are more easily identified; there is ability to mobilize resources for the necessary education; having the screening tool in use helps with identification of learning needs and helps with setting performance appraisal goals 
400 participants, including international participants. Evaluation suggests the program is highly effective in increasing nurses' confidence with screening, providing supportive counselling and making complex referrals. In particular, videotaped examples of nurses discussing screening results and providing initial intervention were identified as very effective in helping nurses to address patient needs (McLeod \& Morck, 2011). Although these education initiatives are helpful, ongoing support and mentoring would strengthen the learning obtained through formal programs such as this.

\section{Conclusion}

Oncology nurses have a critical function to provide high-quality, comprehensive patient care by screening for distress (sixth vital sign). As direct care providers of psychosocial care and symptom management, oncology nurses can use a standardized screening tool on a routine basis to initiate dialogue with a patient, focus their assessment and establish an intervention approach that is personcentred and relevant to identified concerns and sources of distress. Using the tool will clearly identify those individuals who would benefit from additional assessment and intervention and help to prioritize care and actions taken. Nurses are critical in early identifi-

\section{References}

Adler, N.E., \& Page, A.E.K. (Eds.). (2008). Cancer care for the whole patient: Meeting psychosocial health needs. Institute of Medicine. Washington, DC: The National Academic Press.

Arnold, E. (1999). Communication with clients in stressful situations. In E. Arnold \& K.U. Boggs (Eds.), Interpersonal relationships: Professional communication skills by nurses (3rd ed.). Toronto, ON: W.B. Saunders Company Inc.

Barney, L.J., Griffiths, K.M., Christensen, H., \& Jorm, A.F. (2009). Exploring the nature of stigmatizing beliefs about depression and help-seeking: Implications for reducing stigma. BMC Public Health, 9, 61-69. doi:10.1186/1471-2458-9-61

Botti, M., Endacott, R., Watts, R., Cairns J., Lewis, K., \& Kenny, A. (2006). Barriers in providing psychosocial support for patients with cancer. Cancer Nursing, 29(4), 309-316.

Brown, K.W., Levy, A.R., Rosberger, Z., \& Edgar, L. (2003). Psychological distress and cancer survival: A follow-up 10 years after diagnosis. Psychosomatic Medicine, 65, 636-643. doi:10.1097/01.PSY.0000077503.96903.A6

Bruera, E., Kuehn, N., Miller, M.J., Selmser, P., \& Macmillan, K. (1991). The Edmonton Symptom Assessment System (ESAS): A simple method of assessment of palliative patients. Journal of Palliative Care, 7, 6-9.

Bultz, B., \& Carlson, L. (2006). Emotional distress: The sixth vital sign-future directions in cancer care. Psycho-Oncology, 15, 93-95. doi:10.1002/pon.1022

Canadian Association of Nurses in Oncology/Association canadienne des infirmieres en oncologie (CANO/ACIO). (1995). Standards for oncology nursing practice. Toronto, ON: CANO/ACIO.

Canadian Partnership Against Cancer. (2009). Cancer System Quality Index (2010). Toronto: Cancer Care Ontario.

Cancer Care Ontario. (2011). Symptom Management Guides. Retrieved from http://www.cancercare.on.ca/toolbox/symptools

Carlson L.E., \& Bultz, B.D. (2004). Efficacy and medical cost offset of psychosocial interventions in cancer care: Making the case for economic analyses. Psycho-Oncology, 13, 837-849. doi:10.1002/ pon. 832

Carlson L.E., Angen, M., Cullum J., et al. (2004). High levels of untreated distress and fatigue in cancer patients. Br J Cancer, 90, 2297-2304. doi:10.1038/sj.bjc.6601887

Carlson, L., \& Bultz, B. (2003). Benefits of psychosocial oncology care: Improved quality of life and medical cost offset. Health Quality of Life Outcomes, 1, 8. doi:10.1186/1477-7525-1-8 cation of distress and facilitating access to quality care and needed resources. Early lessons from oncology nurse leaders emphasize the need for leaders to articulate and fundamentally support the role and responsibilities of nursing staff in screening, as a triage manoeuvre/step and demystify screening for distress with direct care staff members.

Ultimately, implementing screening for distress and responding effectively will require an inter-professional team effort with a strong emphasis placed on the responsibility of the direct care oncology team working in partnership with other specialists. It is important to ensure the processes for implementation are clear and well conceived and that staff is highly involved in planning the implementation together with nurse leaders. When screening for distress is conceptualized and supported as an integral part of oncology nursing care, there will be change in practice and workflow. Such change can increase the quality of care for cancer patients if addressed strategically and supported by adequate education, resources such as symptom management guides, and mentoring. Education, guides, and mentoring can lead to enhanced job satisfaction for nurses who are empowered to practice to the full scope of their capabilities.

Cleeland, C.S., Gonin, R., Hatfield, A.K., Edmonsen, J.H., Blum, R.H., Stewart, J.A., \& Panya, K.J. (1994). Pain and its treatment in outpatients with metastatic cancer. N Engl J Med, 330, 592-596.

Corner, J. (1996). Beyond survival rates and side effects: Cancer nursing as therapy (Robert Tiffany Address). 9th International Conference on Cancer Nursing. Brighton, UK.

Coyne, J.C., Thompson, R., Palmer, S.C., Kagee, A., \& Maunsell, E. (2000). Should we screen for depression? Caveats and potential pitfalls. Applied \& Preventive Psychology, 9, 101-121. doi:10.1016/S0962-1849(00)80009-8

Fallowfield, L., Ratcliffe, D., Jenkins, V., \& Saul, J. (2001). Psychiatric morbidity and its recognition by doctors in patients with cancer. Br J Cancer, 84, 1011-1015. doi:10.1054/bjoc.2001.1724

Fisch, M. (2004). Treatment of depression in cancer. J Natl Cancer Inst Monogr, 32, 105-111. doi:10.1093/jncimonographs/lgh011

Fitch, M.I. (In press). Supportive care needs of patients with advanced disease undergoing radiotherapy for symptom control. Canadian Oncology Nursing Journal.

Fitch, M.I. (2008). Supportive Care Framework: Theoretical Underpinnings. In M.I. Fitch, H.B. Porter \& B.D. Page (Eds.), Supportive Care Framework: A foundation for person-centred care. Pembroke, ON: Pappin Communications.

Folkman, S., \& Greer, S. (2000). Promoting psychological well-being in the face of serious illness: When theory, research and practice inform each other. Psycho-Oncology, 9, 11-19.

Fulcher, C.D., Badger, T., Gunter, A.K., \& Marrs, J.A. (2008). Putting evidence into practice: Interventions for depression. Clin J Oncol Nur, 12(1), 131-140. doi:10.1188/08.CJON.131-140

Gerteis M., Edgman-Levitan S., Daley J., \& Delbanco, T.L. (1993). Through the Patient's Eyes: Understanding and Promoting PatientCentered Care. San Francisco, CA: Jossey-Bass.

Given, B., \& Sherwood, R.R. (2005). Nursing sensitive patient outcomes: A white paper. Oncology Nursing Forum, 32(4), 15381688. doi:10.1188/05.ONF.773-784

Groenvold, M., Petersen, M.A., Idler, E., Bjorner, J.B., Fayers, P.M., \& Mouridsen, H.T. (2007). Psychological distress and fatigue predicted recurrence and survival in primary breast cancer patients. Breast Cancer Res Treat, 105, 209-219. doi:10.1007/s10549-006-9447-x

Grunfeld, E., Coyle, D., Whelan, T., Clinch, J., Reyno, L., Earle, C.C., et al. (2004). Family caregiver burden: Results of a longitudinal study of breast cancer patients and their principal caregivers. Canadian Medical Association Journal, 170, 1795-1801. doi:10.1503/cmaj.1031205 
Hack, T.F., Degner, L.F., \& Parker, P.A. (2005). The communication goals and needs of cancer patients: A review. Psycho-Oncology, 14(10), 831-845. doi:10.1002/pon.94

Holland, J.C., Kelly, B.J., \& Weinberger, M.I. (2010). Why psychosocial care is difficult to integrate into routine cancer care: Stigma is the elephant in the room. J Natl Compr Canc Netw, 8(4), 362-366.

Howell, D. (2010). Psychological distress as a nurse sensitive outcome. In D. Doran (Ed.), Nurse Outcomes; State of the Science (pp. 285-358). Mississauga, ON: Jones \& Bartlett Publishers Inc.

Howell, D., Currie, S., Mayo, S., Jones, G., Boyle, M., Hack, T., Green, E., Hoffman, L., Simpson, J. Collacutt, V., McLeod, D. \& Digout, C. (2009, mai). Guide pancanadien de pratique clinique: évaluation des besoins en soins psychosociaux du patient adulte atteint de cancer, Toronto, Partenariat canadien contre le cancer (groupe d'action pour l'expérience globale du cancer) et Association canadienne d'oncologie psychosociale.

Institute of Medicine (IOM). (2008). Cancer care for the whole patient: Meeting psychosocial health needs. Nancy E. Adler and Ann E.K. Page, Eds. Washington, DC: The National Academies Press.

Jacobsen, P.B. (2009). Promoting evidence-based psychosocial care for cancer patients. Psycho-Oncology, 18(1), 6-13. doi:10.1002/ pon. 1468

Jacobsen, P.B., Shibata, D., Siegel, E.M., Lee, J., Alemany, C.A., Brown, R., et al. (2009). Initial evaluation of quality indicators for psychosocial care of adults with cancer. Cancer Control, 16(4), 328-334.

Kennard B.D., Smith S.M., Olvera, R., et al. (2004). Nonadherence in adolescent oncology patients: Preliminary data on psychological risk factors and relationships to outcome. J Clin Psych Medical Settings, 11, 30-39. doi:10.1023/B:JOCS.0000016267.21912.74

Kleinpell, R.M. (2001). Outcome assessment in advanced practice nursing. New York, NY: Springer Publishing Company Inc.

Lepore, S.L., \& Coyne, J.C. (2006). Psychological interventions for distress in cancer patients: A review of reviews. Annals of Behavioral Medicine, 32(2), 85-92. doi:10.1207/s15324796abm3202_2

Longo, C.J., Fitch, M., Deber, R.B., \& Williams, A.P. (2006). Financial and family burden associated with cancer treatment in Ontario, Canada. Supportive Care in Cancer, 14, 1077-1085. doi:10.1007/ s00520-006-0088-8

McCaffery, M., \& Pasero, C. (1999). Pain: Clinical Manual (2nd ed.). St. Louis, MO: Mosby.

McCloskey, J., \& Bulechek, G. (1996). NIC: Nursing Intervention Classification System. St. Louis, MO: Mosby.

McCormack, B., \& McCance, T.V. (2006). Development of a framework for person-centered nursing. Journal of Advanced Nursing, 56(5), 472-479. doi:10.1111/j.1365-2648.2006.04042.x

McLeod, D.L., Tapp, D.M., Moules, N.J., \& Campbell, M.E. (2010). Knowing the family: Interpretations of family nursing in oncology and palliative care. European Journal of Oncology Nursing, 14(2), 93-100.

McLeod, D., \& Morck, A. (2011). Screening for Distress, the 6th Vital Sign: Outcomes of a web-based education resources to support a national screening for distress program. Paper presented at the Canadian Association of Psychosocial Oncology, May 5, 2011, Toronto, Ontario.

Merckaert, I., Libert, Y., Delvaux, N., Marchal, S., Boniver, J., Etienne, A.M., Klastersky, J., ... Razavi, D. (2005). Factors that influence physicians' detection of distress in patients with cancer: Can a communication skills training program improve physicians' detection? Cancer, 104(2), 411-421.

Mitchell, A.J., \& Kakkadasam, V. (2010). Ability of nurses to identify depression in primary care, secondary care and nursing homes: A meta-analysis of routine clinical accuracy. International Journal of Nursing Studies, 48(3), 359-368. doi: 10.1016/ j.ijnurstu.2010.05.012

Mitchell, A.J., Hussain, N., Grainger, L., \& Symonds, P. (2010). Identification of patient-reported distress by clinical nurse specialists in routine oncology practice: A multicentre UK study. Psycho-Oncology, 20(10), 1076-1083. doi: 10.1002/pon.1815

National Comprehensive Cancer Network (NCCN). (2010). Distress Management. Retrieved from http://www.nccn.org/ professionals/physician_gls/f_guidelines.asp

National Institute for Clinical Excllence (NICE). (2004). Improving supportive and palliative care for adults with cancer: Executive Summary. London, England.

Newell, S.A., Sanson-Fisher, R.W., Savolainen, N.J. (2002). Systematic review of psychological therapies for cancer patients: Overview and recommendations for future research. J Natl Cancer Inst, 94, 558-584. doi:10.1093/jnci/94.8.558

Patrick, D.L., Ferketich, S.L., Frame, P.S., Harris, J.J., Hendricks C.B., Levin, B., et al. (2003). National Institutes of Health Stateof-the-Science Conference Statement: Symptom Management in Cancer - Pain, Depression and Fatigue, July 15-17, 2002. J Natl Cancer Inst, 95(15), 1110-1117. doi:10.1093/jnci/djg014

Plummer, S.E., Gourney, K., Goldberg, D., Ritter, S.A., Mann, A.H., \& Blizard, R. (2000). Detection of psychosocial distress of practice nurses in general practice. Psychology Med, 15, 863-872.

Programme Qmentum, Services de traitement du cancer et oncologie. (2010). Agrément Canada : Ottawa. http://www.accreditation.ca/ fr/content.aspx?pageid=50\&langType=3084 (voir « Les normes » à gauche)

Richardson, A., Medina, J., Brown, V., \& Sitzia, J. (2007). Patients' needs assessments in cancer care: A review of assessment tools. Supportive Care in Cancer, 15(10), 1125-1144. doi:10.1007/ s00520-006-0205-8

Sanson-Fisher, R.W., Girgis, A., Boyes, A., Bonevski, B., Burton, L., Cook, P., et al. (the Supportive Care Review Group). (2000). The unmet supportive care needs of patients with cancer. Cancer, 88 , 226-237.

Skarstein, J., Aass, N., Fossa, S.D., Skovlund, E., \& Dahl, A.A. (2000). Anxiety and depression in cancer patients: Relation between the Hospital Anxiety and Depression Scale and the European Organization for Research and Treatment of Cancer Core Quality of Life Questionnaire. J Psychosom Res, 49, 27-34.

Steele, R., \& Fitch, M. (2008). Why patients with lung cancer do not want help with some needs. Supportive Care in Cancer, 16(3), 251-259. doi: 10.1007/s00520-007-0301-4

Steele, R., \& Fitch, M. (2008). Supportive care needs of women with gynecological cancer. Cancer Nursing, 31(4), 284-291. doi:10.1097/01.NCC.0000305743.64452.30

Stewart, M. (2001). Towards a global definition of patient-centered care. BMJ, 322, 444-445. doi:10.1136/bmj.322.7284.444

Union for International Cancer Control (UICC). (2010). World Cancer Congress, Shenchen, China.

Vachon, M. (2006). Psychosocial distress and coping after cancer treatment. Cancer Nursing, 29(2 Suppl.), 26-31.

Vachon, M.L. (1998). Psychosocial needs of patients and families. Journal of Palliative Care, 14, 49-53.

Vodermaier A., \& Linden W. (2008). Emotional distress screening in Canadian Cancer Care. Oncology Exchange, 7(4), 37-40.

Von Essen, I., Larsson, G., Oberg, K., \& Sjoden, P.O. (2002). Satisfaction with care: Associations with health-related quality of life and psychosocial function among Swedish patients with endocrine and gastrointestinal tumors. Eur J Cancer Care, 11, 91-99.

Weisman A.D. (1976). Early diagnosis of vulnerability in cancer patients. Am J Med Sci, 271, 187-196.

Wen, K.Y., \& Gustafson, D.H. (2004). Needs assessment for cancer patients and their families. Health and Quality of Life Outcomes, 2, 11. doi:10.1186/1477-7525-2-11

Zabora, J., BrintzenhofeSzoc, K., Curbow, B., Hooker, C., \& Piantadosi, S. (2001). The prevalence of psychological distress by cancer site. Psycho-Oncology, 19(1), 19-28. 